\title{
Comparison of drug-related problem risk assessment tools for older adults: a systematic review
}

\author{
Emmi Puumalainen ${ }^{1}$ (D) Marja Airaksinen ${ }^{1} \cdot$ Sanni E. Jalava ${ }^{1} \cdot$ Timothy F. Chen $^{2} \cdot$ Maarit Dimitrow $^{1}$
}

Received: 28 April 2019 / Accepted: 5 November 2019/Published online: 10 December 2019

(C) The Author(s) 2019

\begin{abstract}
Purpose This study aims to systematically review studies describing screening tools that assess the risk for drug-related problems (DRPs) in older adults ( $\geq 60$ years). The focus of the review is to compare DRP risks listed in different tools and describe their development methods and validation.

Methods The systematic search was conducted using evidence-based medicine, Medline Ovid, Scopus, and Web of Science databases from January 1, 1985, to April 7, 2016. Publications describing general DRP risk assessment tools for older adults written in English were included. Disease, therapy, and drug-specific tools were excluded. Outcome measures included an assessment tool's content, development methods, and validation assessment.

Results The search produced 15 publications describing 11 DRP risk assessment tools. Three major categories of risks for DRPs included (1) patient or caregiver related risks; (2) pharmacotherapy-related risks; and (3) medication use process-related risks. Of all the risks included in the tools only 8 criteria appeared in at least 4 of the tools, problems remembering to take the medication being the most common $(n=7)$. Validation assessments varied and content validation was the most commonly conducted $(n=9)$. Reliability assessment was conducted for 6 tools, most commonly by calculating internal consistency $(n=3)$ and inter-rater reliability $(n=2)$.

Conclusions The considerable variety between the contents of the tools indicates that there is no consensus on the risk factors for DRPs that should be screened in older adults taking multiple medicines. Further research is needed to improve the accuracy and timeliness of the DRP risk assessment tools.
\end{abstract}

Keywords Drug-related problem $\cdot$ Risk management $\cdot$ Geriatrics $\cdot$ Mass screening $\cdot$ Risk assessment $\cdot$ PRISMA statement

\section{Introduction}

Drug-related risk management has become an important area of research in patient safety. It is estimated that approximately half of the drug-related incidents contributing to severe harm could be prevented by managing risks through interventions at different points of the medication use process [1]. The World Health Organization's (WHO) program, Medication Without Harm, aims

Electronic supplementary material The online version of this article (https://doi.org/10.1007/s00228-019-02796-w) contains supplementary material, which is available to authorized users.

Emmi Puumalainen

emmi.puumalainen@helsinki.fi

1 Faculty of Pharmacy, University of Helsinki, Helsinki, Finland

2 Faculty of Medicine and Health, University of Sydney, Sydney, Australia to globally reduce severe avoidable drug-related harm by $50 \%$ in 5 years [2]. Drug-related risk management aims at reducing medication errors that might potentially or actually cause drug-related problems (DRPs) or risk of DRPs [3]. A DRP is an event or circumstance involving drug therapy that actually or potentially interferes with desired health outcomes (PCNE) [4]. Another definition for a DRP emphasizes that a DRP can either cause harm or result in medication treatment not reaching its goal [5].

Identification of actual or potential risk factors for DRPs should be considered an essential part of safe medication use particularly in older adults. Although there is considerable research on explicit criteria assessing inappropriate prescribing, these criteria mainly target a small part of the whole problem [6]. DRP's can occur in any phase of the medication use process. Through DRP risk identification in patient selection for different interventions, DRPs can be identified and resolved with a more targeted approach. DRP risk assessment tools have been developed taking into consideration special features of geriatric patients. However, the content of these 
tools have not been systematically reviewed. The objective of this study was to systematically review the content of screening tools intended for assessing risks for DRPs in older adults ( $\geq 60$ years). The focus of the review was to compare DRP risk factors in different tools and describe the methods applied in their development and validation.

\section{Methods}

\section{Search strategy and literature search}

This systematic review conformed to the PRISMA checklist $[7,8]$. The evidence-based medicine (EBM), Scopus, and Web of Science (WOS) databases were searched from January 1, 1985, till April 6, 2016 and Medline Ovid database from January 1, 1985, till April 7, 2016 for eligible publications. The search terms used in the systematic search were ((elderly OR aged OR ageing) AND ("medication-related problem*" OR "drug-related problem*" OR "drug therapy problem*" OR "medicine-related problem*" OR "medication management problem*" OR "therapy-related problem* OR "DRP*") AND (risk OR risk assessment) AND (screen OR "screening tool" OR form OR assessment* OR evaluation* OR indicator* OR criteria OR survey* OR questionnaire* OR factor* OR "risk factor*)). CINAHL database was included in the pilot search but was excluded from further searches because of a very low number of potentially relevant publications. Thus, the results for the CINAHL database are reported according to the pilot search on October 29, 2013.

The publications found in the searches $(n=4279)$ were first evaluated according to the predetermined inclusion and exclusion criteria (Table 1) by one of the authors (EP) by reading the title (Fig. 1). Then two authors (EP and SJ) assessed the publications independently by reading the abstract $(n=196)$ and finally by reading the whole text $(n=54)$. Duplicates $(n=$
34) were excluded before reading the full-texts. Any disagreements were resolved through discussion. Reasons for exclusion of the full-text publications $(n=44)$ are reported in Fig. 1 . A manual search of the references and author's own collection of publications was conducted (EP), and 5 publications meeting inclusion criteria were discovered, one of which was not explicitly meant for older adults [9]. This publication was included in the review due to its importance for development of other DRP risk assessment tools. Of these five publications, two were received from the authors of included publications as additional information $[10,11]$. Manually researched publications were also assessed by a second assessor (SJ).

To get insight into the clinical use and clinical validation of these screening tools, we contacted the authors of the publications. For those screening tools, we were unable to contact the author we made an additional search from the Medline database to find the publications that cited the original screening tool. From these sources, we were able to find publications describing clinical use or validation in patient surroundings.

\section{Data extraction and analysis}

Country of origin, criteria contents, setting in which the tool is meant to be used, development methods, and the evidence used to determine the criteria, nature of the criteria (explicit/ implicit), the primary user of the tool, and information on the primary validity or reliability of the tool were analyzed. Also information on clinical use and validation was extracted.

\section{Results}

This systematic review identified 15 publications describing 11 DRP risk assessment tools, 10 of which were specially designed for older adults aged 60 years and above (Fig. 1, Tables 2 and 3 and Online Resource 1). The general tool,
Table 1 Inclusion and exclusion criteria used in the literature search

\begin{tabular}{|c|c|}
\hline Inclusion criteria & Exclusion criteria \\
\hline $\begin{array}{l}\text { Patients } \geq 60 \text { years old (evidence-based medicine, } \\
\text { Scopus, Web Of Science, Medline). Patients } \\
\geq 65 \text { years old (CINAHL) }\end{array}$ & Patients $<60$ years old. (CINAHL $<65$ years old) \\
\hline English & Language other than English \\
\hline $\begin{array}{l}\text { Describes a general drug-related problem risk } \\
\text { assessment tool }\end{array}$ & $\begin{array}{l}\text { Describes a disease, therapy, and drug-specific tool or } \\
\text { a tool focusing solely on inappropriate prescribing } \\
\text { or adherence }\end{array}$ \\
\hline $\begin{array}{l}\text { Describes the end user of the tool and in what setting it } \\
\text { is meant to be used }\end{array}$ & $\begin{array}{l}\text { Does not describe by whom and in what setting the } \\
\text { tool is meant to be used }\end{array}$ \\
\hline $\begin{array}{l}\text { Published between January 1, 1985-April 7, } 2016 \\
\text { (CINAHL January 1, 1985-October 29, 2013) }\end{array}$ & Published before January 1,1985 , or after April 7, 2016 \\
\hline The tool focuses on older population in general & $\begin{array}{l}\text { The tool focuses on other than older population or only } \\
\text { on a certain part of the older population, e.g., having } \\
\text { the same disease or drug therapy }\end{array}$ \\
\hline Published in a peer-reviewed journal & Published in other than peer-reviewed journal \\
\hline
\end{tabular}


Potentially relevant publications $(\mathrm{n}=4279)$

(Evidence Based Medicine (EBM), n=81; Medline, n=519; Web of Science (WOS), n=191; Scopus, n=727; Cinahl, $\mathrm{n}=2761$ )

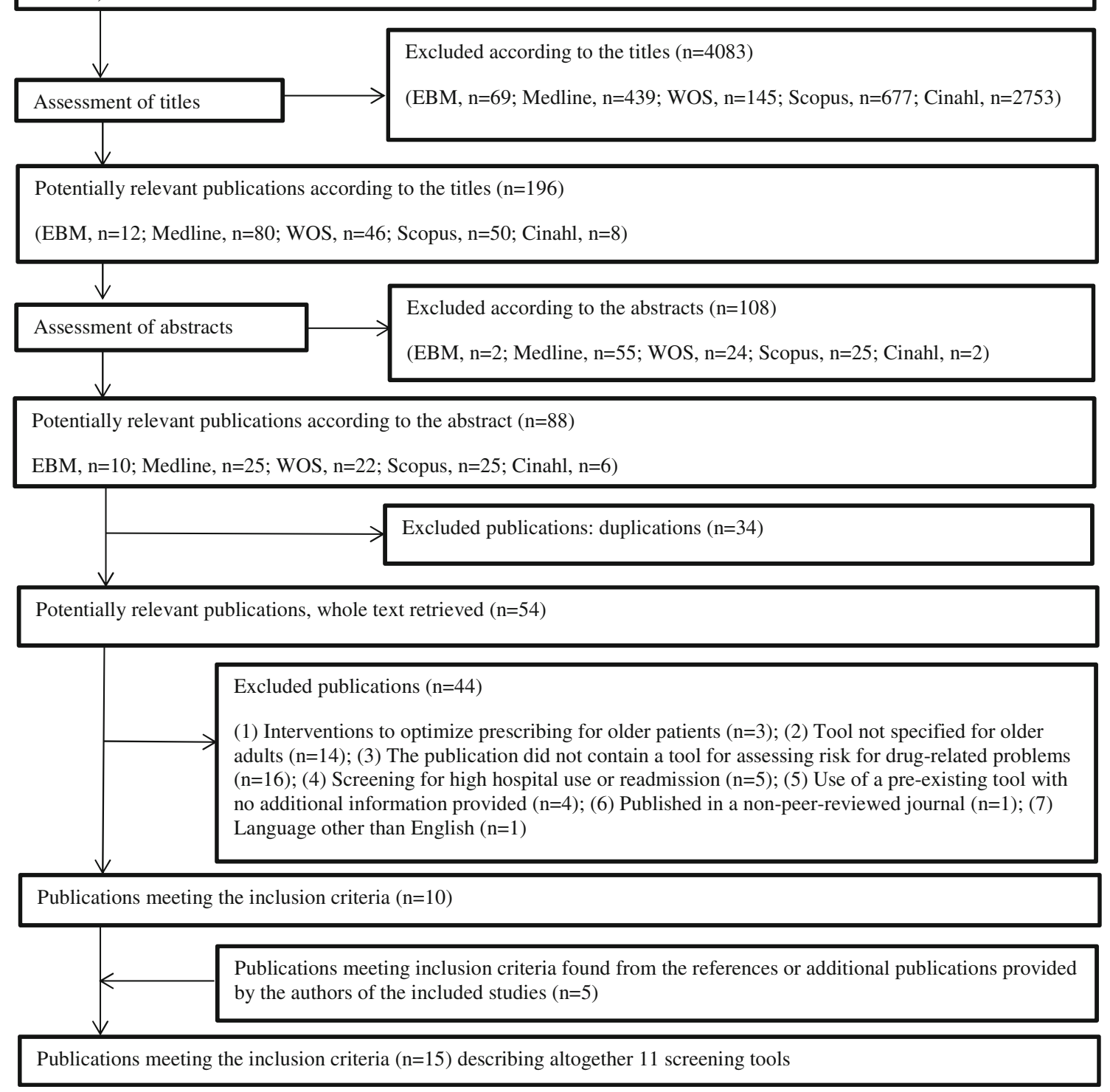

Fig. 1 Flowchart of the study

without age specifications, was the earliest tool, published in 1989 [9] and used as a foundation for four other tools developed later [15, 27, 35, 38].

Seven of the tools $(64 \%)$ were intended to be used in primary care, mostly in home care or community nursing $(n=4)$ $[20,33,34,38]$ (Table 2). Three of the tools targeted ambulatory care [9, 14, 15], one focused on intermediate care [27], and one targeted computer screening of risks for DRPs [34]. Nearly all $(n=10 / 11)$ of the tools were developed to be used explicitly [9, 15, 17, 20, 27, 30, 33-35, 38]. Two of the tools had an established scoring system making the interpretation of the results explicit $[14,17]$. Four of the tools were designed to be completed by the patient $[15,27,30,35]$. Four tools were designed to be used by pharmacists [9, 14, 17, 34] or nurses $[17,20,33,38]$, while two of the tools had several possible end users [17, 38].

\section{Contents of the tools}

The risk assessment tools encompassed 4-71 criteria, seven of the tools containing less than 20 criteria (Tables 3 and Online Resource 1). These criteria were divided into three main risk categories: patient or caregiver-related risks, pharmacotherapy-related risks, and medication use processrelated risks (Online Resource 1). The patient or caregiverrelated risks included older age, multiple comorbidities, and 


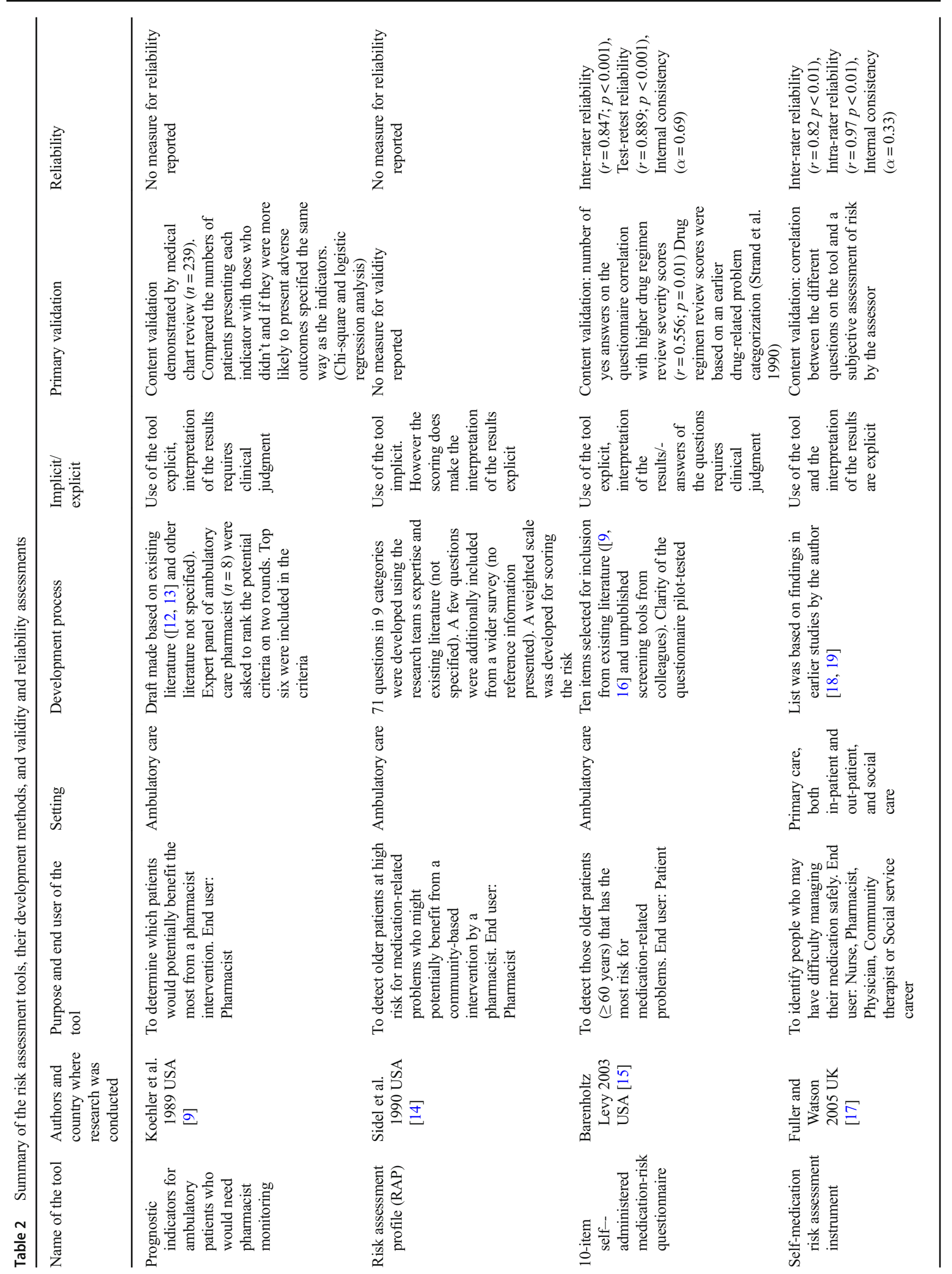




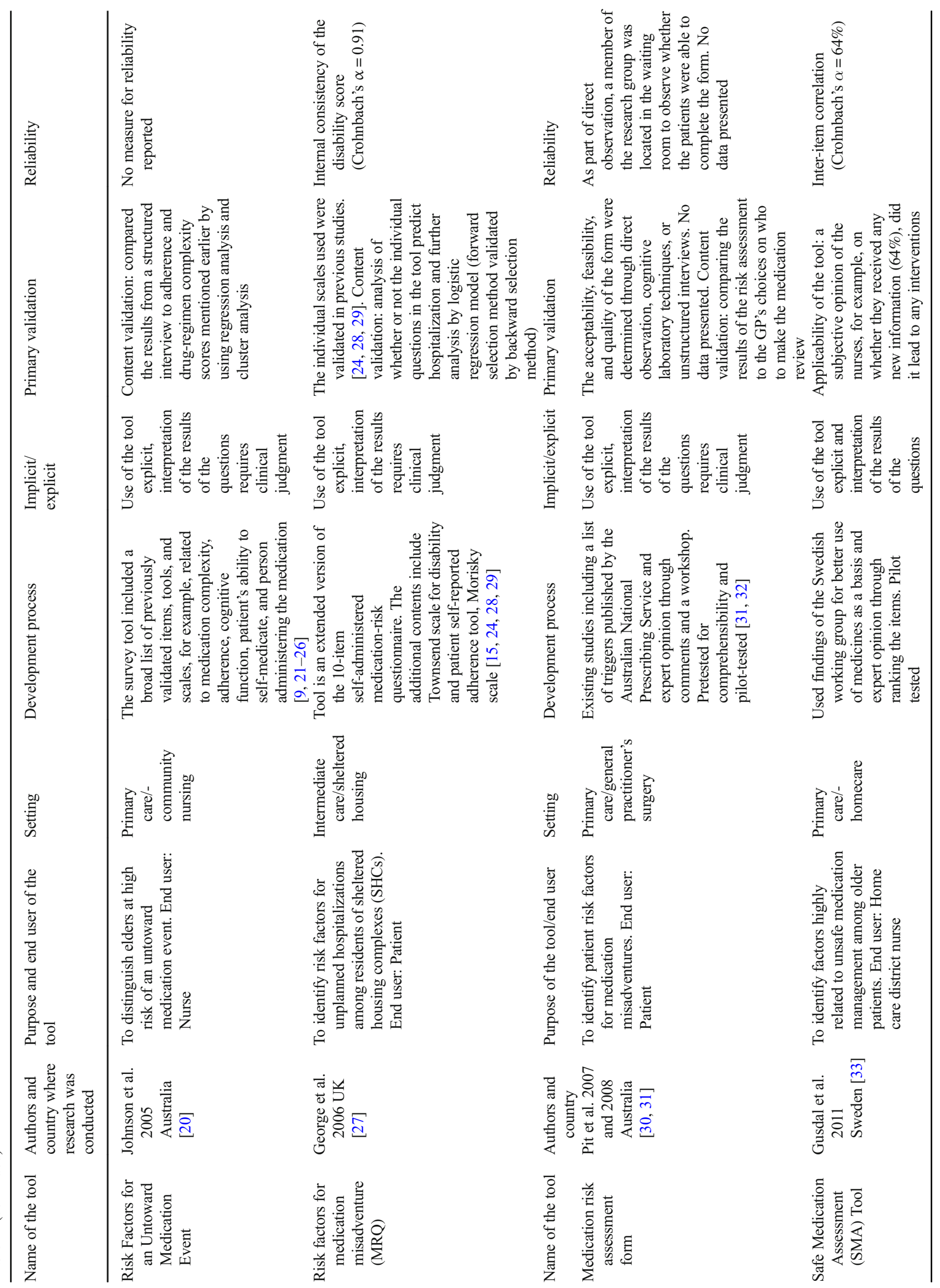




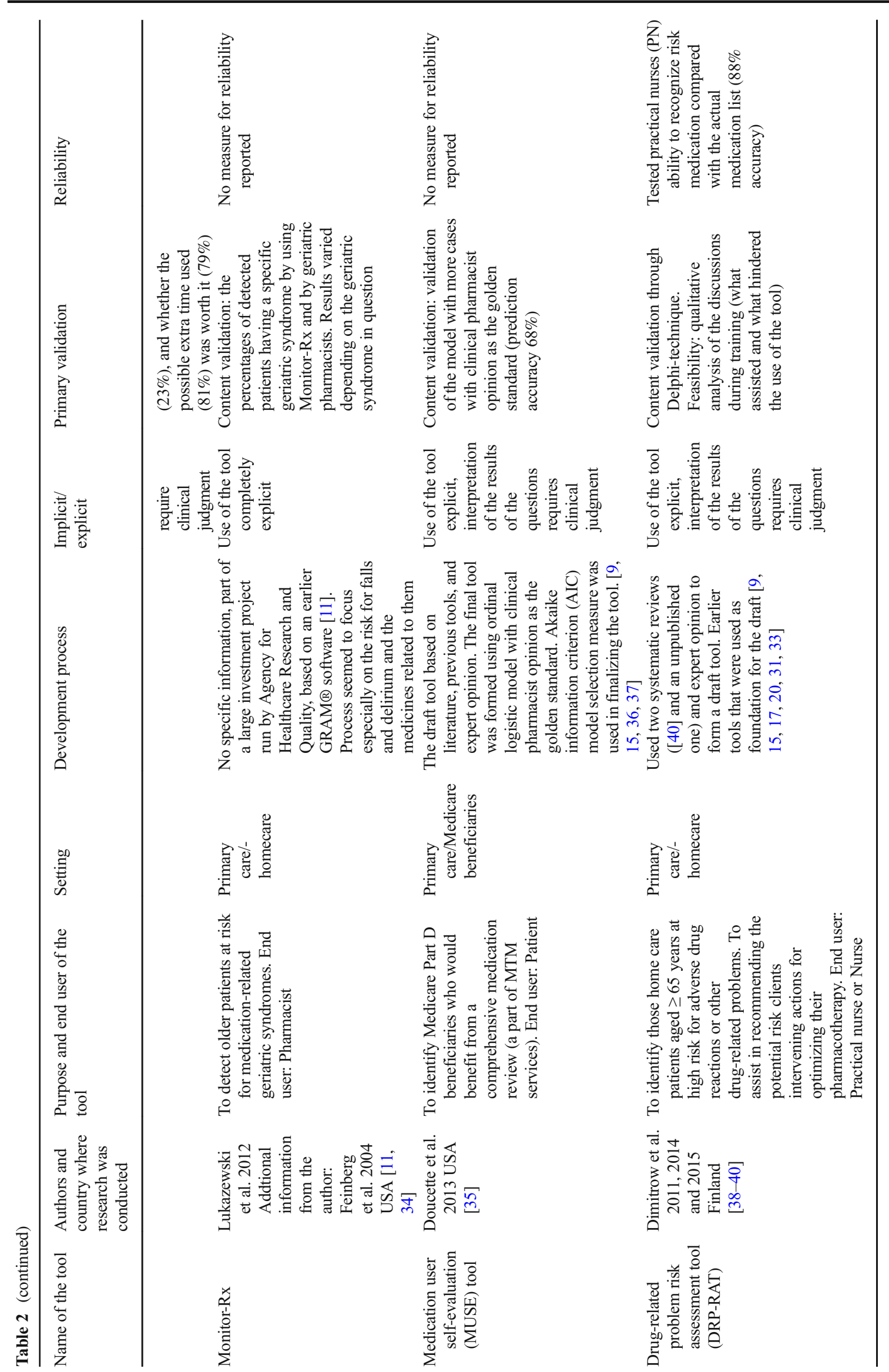


medication adherence or self-management problems as risk factors for clinically significant DRPs. The items concerning medication adherence and self-management demonstrated more variety between the tools compared to any other risk categories. Pharmacotherapy-related risks most commonly indicated risks caused by polypharmacy, potentially inappropriate medications for older adults (PIMs), potential ADRs, and recent changes in medication regimen. Most common PIMs listed in the tools included carbamazepine $(n=3)[15,27,38]$, digoxin $(n=3)[15,27,38]$, lithium $(n=3)[15,27,38]$, theophylline $(n=3)[15,27,38]$, and warfarin $(n=3)[15,27$, 38]warfarin $(\mathrm{n}=3)(\mathrm{ref})$. The most common potential ADRs were classified as drowsiness $(n=2)$ [30,38], visual problems $(n=2)[14,38]$, nausea $(n=2)[30,38]$, constipation $(n=2)$ $[30,38]$, skin rash $(n=2)[30,38]$, and dizziness $(n=2)$ [30, $38]$. The tools included a few risks related to the medication use process such as health service visits, number of physicians involved in patient's care, and living arrangements.

The most common risks that appeared in at least four of the tools were established (Tables 3 and Online Resource 1). "Problems remembering to take the medication" was the most frequent item and was included in seven of the tools [14, 20, $27,30,33,35,38]$. Only one of the tools gave options for resolving the risks identified [38].

\section{Validity and reliability}

The primary validity of the tool was assessed more commonly $(n=9)$ than reliability $(n=6)$ (Tables 2 and 3). For one of the tools, validation was not reported [14], and reliability was not assessed for five of the tools $[9,14$, $20,34,35]$. There seemed to be no consistent type of validity or reliability assessment. Content validation $(n=$ 9) $[9,15,17,27,30,34,35,38]$ and assessing the applicability of the tool $(n=3)[30,33,38]$ were the most common types of validation. Internal consistency $(n=3)$ $[15,17,27]$ and inter-rater reliability $(n=2)[15,17]$ were the most common types of reliability assessment.

The outcome variables used for primary validation varied from study to study. For example, number of recognized risk factors (intervention group vs. control group) and measures used to assess adherence and medication regimen complexity were used as outcomes in different studies. Also it is worth noting that validation of the scoring was not reported for both tools that had a scoring system $[14,17]$. The most comprehensive evaluation of primary validity and reliability were done in Barenholz-Levy's, Fuller and Watson's, Gusdal's, and Dimitrow's research $[15,17,33,38]$.

Additional clinical validation $[10,41]$ was done only for two of the screening tools (Table 4 ) $[15,38]$. Three of the tools $[9,15,38]$ were reported in clinical use in scientific publications [42-50].

\section{Discussion}

This is the first systematic review evaluating and comparing the content and development processes of published criteria for DRP risk assessment for older adults. It provides insights into the evidence and content of DRP risk assessment tools. This information is important because these tools maybe used for clinical decision making, by screening older adults at risk for DRPs.

Our systematic review found considerable variety in the number and contents of the criteria included in the risk assessment tools; only eight of the risks were similar between the tools (Problems with remembering to take the medication $(n=$ 7) $[14,20,27,30,33,35,38]$, Not knowing indications for the medicines $(n=5)$ [15, 27, 30, 33, 38], More than one physician involved in patient's care $(n=5)[15,20,27,30,38], \geq 12$ doses per day $(n=5)[9,15,20,27,38], \geq 5$ medicines in use $(n=4)[9,15,27,30], \geq 3$ illnesses $(n=4)[15,27,30,38], \geq 4$ changes in the medication regimen within the last year $(n=4)$ $[9,15,27,30]$, and Problems taking medicine out of the bottle or using a dose dispenser or therapeutic devises $(n=4)[14$, $30,33,38])$. The different settings and end users they were designed for may partly explain the variety in the content of the tools. Four of the tools were designed for patients $[15,27$, $30,35]$, and the rest for healthcare professionals $[17,20,33$, 38]. The earliest tool was published two decades ago [9], and the most recent was published in 2014 [38]. This time period corresponds to the publication of criteria used in the assessments of PIMs, which may partially explain the different content of the tools. Five of the tools used previously published tools as a basis for the development $[15,20,27,35,38]$. This may be considered a strength if the tool used as a foundation was developed through a rigorous method and is well validated. The data that is used should not be outdated but represent the knowledge of risks for DRPs in the elderly population at the time of publication. The critical evaluation of the previous criteria is needed if the specific criteria are to be used as a foundation for a new risk assessment tool. The use of previous tools might bring more evidence and validity for the new tool but might also limit the ingenuity and timeliness of the contents of the new tools.

The primary validity and reliability assessments of the tools varied substantially. Content validation was done for most of the tools $(n=9 / 11)[9,15,17,20,27,30,34,35,38]$, while two of the tools $[14,33]$ were not assessed for content validity which is a significant limitation [51]. Five of the tools [9, 30, $33,35,38]$ used expert opinion in their development process, but only one of them was further validated using the Delphi method [38]. Two other tools used expert opinion consensus to rank the items that would be included in the final tool in one or more rounds $[9,33]$. A recent review on methodology to assess content validity highlights the importance of determining content validity for new instruments [51]. The 
Table 3 Summary of the characteristics of the drug-related problem risk assessment tools $(n=11)$

$\begin{array}{ll}\text { Country of origin } & \text { USA }(n=5)[9,14,15,34,35] \\ & \text { UK }(n=2)[17,27] \\ & \text { Australia }(n=2)[20,30] \\ & \text { Sweden }(n=1)[33] \\ & \text { Finland }(n=1)[38] \\ \text { Setting } & \text { Primary care }\end{array}$

Homecare or community nursing $(n=4)[20,33,34,38]$

General practitioner's surgery $(n=1)$ [30]

Medicare beneficiaries $(n=1)[35]$

Primary care and social care $(n=1)[17]$

Ambulatory care $(n=3)[9,14,15]$

Use of the tool implicit / explicit

Intermediate care/sheltered housing $(n=1)$ [27]

Explicit $(n=10)[9,15,17,20,27,30,33-35,38]$

Implicit $(n=1)$ [14]

Number of criteria

$1-4$ criteria $(n=1)$ [20]

5-9 criteria $(n=3)[9,17,35]$

$10-14$ criteria $(n=1)[15]$

$15-19$ criteria $(n=2)[27,33]$

20-29 criteria $(n=1)$ [38]

30-34 criteria $(n=1)$ [30]

$\geq 35$ criteria $(n=1)[14]$

Unknown $(n=1)$ [34]

The most common risks that

Problems with remembering to take the medication $(n=7)[14,20,27,30,33,35,38]$

appeared in at least four of the tools

Not knowing indications for the medication $(n=5)[15,27,30,33,38]$

More than one physician involved in patient's care $(n=5)[15,20,27,30,38]$

$\geq 12$ doses per day $(n=5)[9,15,20,27,38]$

$\geq 5$ medicines in use $(n=4)[9,15,27,30]$

$\geq 3$ illnesses $(n=4)$ [15, 27, 30, 38]

$\geq 4$ changes in the medication regimen within the last year $(n=4)[9,15,27,30]$

Problems taking medicine out of the bottle or using a dose dispenser or therapeutic devises $(n=4)[14,30,33,38]$

End user of the tool*

Patient $(n=4)[15,27,30,35]$

Pharmacist $(n=4)[9,14,17,34]$

Nurse $(n=4)$ [17, 20, 33, 38]

Practical nurse $(n=1)$ [38]

Physician $(n=1)$ [17]

Social service carer $(n=1)[17]$

Community therapist $(n=1)$ [17]

Validity assessment**

Content validation $(n=9)[9,15,17,20,27,30,34,35,38]$

Applicability of the tool $(n=3)[30,33,38]$

No reported validity assessment $(n=1)$ [14]

Reliability assessment**

Internal consistency $(n=3)[15,17,27]$

Inter-rater reliability $(n=2)[15,17]$

Intra-rater reliability $(n=1)$ [17]

Test-retest reliability $(n=1)$ [15]

Inter-item correlation $(n=1)$ [33]

Other assessments $(n=2)[30,38]$

No reported reliability assessment $(n=5)[9,14,20,34,35]$

* Results do not add up to 11 since there could have been several possible end users

**Results do not add up to 11 since several assessments of validity and reliability could have been undertaken 
Table 4 Clinical validation and use of the DRP risk assessment tools

\begin{tabular}{|c|c|c|c|}
\hline Author of the tool & $\begin{array}{l}\text { Information source: } \\
\text { author or Medline }\end{array}$ & Clinical validation & Clinical use \\
\hline Koecheler et al. 1989 [9] & Medline (30 search results) & None & $\begin{array}{l}\text { Malone et al. [42] IMPROVE } \\
\text { study of which there is } \\
\text { considerable amount published [43-47] }\end{array}$ \\
\hline Sidel et al. 1990 [14] & Medline (13 search results) & None & None \\
\hline Barenholz Levy 2003 [15] & Author & $\begin{array}{l}\text { Barenholz Levy and Steffen: significant } \\
\text { correlation with perceived medication } \\
\text { management hassles and reports } \\
\text { of care recipients' falls, injuries, } \\
\text { emergency department visits, unplanned } \\
\text { healthcare visits, CDC Healthy Days, } \\
\text { and amount of unused medications that } \\
\text { interfere with current medication } \\
\text { management. [41] }\end{array}$ & Moore et al. [48]. Tan et al. [49] \\
\hline Fuller and Watson 2005 [17] & Author & None & None \\
\hline Johnson et al. 2005 [20] & Medline (10 search results) & None & None \\
\hline George et al. 2006 [27] & Medline (6 search results) & None & None \\
\hline Pit et al. 2007 [30] & Medline (5 search results) & None & None \\
\hline Gusdal et al. 2011 [33] & Medline (5 results) & None & None \\
\hline Lukazewski et al. 2012 [34] & Author & None & None \\
\hline Doucette et al. 2013 [35] & Author & None & None \\
\hline Dimitrow et. al. 2014 [38] & Author & $\begin{array}{l}\text { Dimitrow et al.: additional content } \\
\text { validation by geriatrician's appraisal } \\
\text { of relevance of the questions. Feasibility } \\
\text { according to a geriatrician's assessment } \\
\text { of the clinically important information } \\
\text { the tool presented. Validity in patient } \\
\text { surroundings and comparison to a } \\
\text { geriatricians risk appraisal with or } \\
\text { without the DRP-RAT. [10] }\end{array}$ & Toivo et al. [50] \\
\hline
\end{tabular}

recommendation of the authors was that content validity processes and indices are critical factors in the instrument development process and should be treated and reported as other types of construct validation. It is also important to keep in mind that every technique used in developing a risk assessment tool has its own limitations [52]. For example, the criteria developed through literature review may not evaluate the quality of evidence. Furthermore, consensus panels, such as Delphi method, only provide knowledge on the opinion of those experts included in the process at that moment in time. These aspects of instrument validation should be considered when deciding which tools will be used in clinical practice. Very few tools were additionally validated or used in clinical settings (Table 4). This presents a further limitation for the evidence-based use of these risk assessment tools.

Most tools $(n=7 / 11)[17,20,30,33-35,38]$ were designed to be used in different primary care settings (homecare or community nursing $(n=4)[20,33,34,38]$, general practitioner's surgery $(n=1)$ [30], Medicare beneficiaries $(n=1)$ [35], and primary care and social care $(n=1)$ [17]) which may partly explain the variety in the risks for DRPs found in the tools. This is in line with findings from Devik et al. [53] from Norway and Leikola et al. from Finland [54]. Both found that DRPs identified in older adults varied in number and in nature depending on whether the patients resided at home or nursing home. These findings demonstrate that the transfer of a tool to a new setting must be accompanied by a new validation of the applicability [51]. That is why tools validated in different settings and for different end users need to be available, which was demonstrated in our systematic review. Also the content and feasibility of the risk assessment tools require regular updating with new research data, pharmacotherapies, and current care guidelines.

No consensus existed in potential ADRs and potentially harmful medication categories listed in the tools. No single risk medication appeared in more than three of the tools, and no single ADR appeared in more than two tools (Online Resource 1). The most common risks for DRPs in the tools were focused on the number of regularly used medicines ( $n=$ 4) $[9,15,27,30]$, number of doses $(n=5)[9,15,20,27,38]$, 
and problems remembering to take the medicines $(n=7)[14$, $20,27,30,33,35,38]$. However, the number of medicines a patient is taking has a limited ability to represent the risk for DRPs [55]. When the patient's medication regimen is planned appropriately, polypharmacy should not be harmful. On the other hand, if the criterion for the risk for DRPs is set, e.g., to 10 medicines, it will exclude many patients at potential risk who have fewer medicines [10]. Two recently established sets of core outcomes measures for trials aimed at improving the appropriateness of polypharmacy in older adults [56] could be useful in guiding further criteria development and standardization of criteria.

\section{Strengths and limitations}

The thorough pilot testing of the search terms, systematic data abstraction, and analysis according to PRISMA Guidelines [7, 8] resulted in a robust search strategy and systematic review process. Notwithstanding this, a variety of terms used to describe DRPs or different kinds of risk assessments for DRPs [5] means that some publications may not have been identified. However, to improve the coverage, we also searched the references of the included articles and contacted the authors in unclear situations. The language was restricted to English, so possible studies published in other languages were excluded. Because of the lack of potentially relevant publications in the CINAHL database in the first phase of the literature search in 2013, it was excluded from the newer search covering the years 2013-2016. The publications were assessed for inclusion by two authors (EP and SJ) by using predetermined inclusion and exclusion criteria. However, data were extracted from the included publications and analyzed by only one of the authors (EP). This might have created bias in this study.

\section{Future studies}

Establishment of new criteria should be continued since only 11 risk assessment tools were located, of which seven tools were developed over 10 years ago and two over 5 years ago. There was considerable variety in essential factors that could cause risk for DRPs. This systematic review provides a good foundation on which to create a better consensus. Current research and recommendations concerning PIM criteria and DRP classifications needs to be taken into account in future research projects.

\section{Conclusions}

The considerable variety between the content of the assessment tools indicates that there was no consensus on the risk factors for DRPs that should be screened in older adults.
Further research is needed to improve the appropriateness and timeliness of the DRP risk assessment tools.

Acknowledgments Open access funding provided by University of Helsinki including Helsinki University Central Hospital. The authors would like to acknowledge the contribution contribution of Dr Ben Basger (PhD, The University of Sydney) Dr. Ben Basger to this research project by commenting the method for conducting the systematic review and Dr Claudia Martin for proof reading. We would like to give our gratitude for Claudia Martin for proof reading.

Author contributions Study concept and design (EP, MA, TC, MD), acquisition of data (EP, SJ, MA, MD), analysis and interpretation of data (EP, MA, MD), and drafting the manuscript and the final approval of the version to be published (EP, MA, SJ, TC, MD).

Funding information We would like to thank the independent Jenny and Antti Wihuri Foundation for funding this research project. Emmi Puumalainen has received a grant of $€ 12,000$ from an independent Jenny and Antti Wihuri Foundation for work on this research project. She has also received travel grants, with a total value of $€ 5050$ from different independent sources for a research exchange at the University of Sydney, Australia, during this research project (University of Helsinki Pharmacy Funds $€ 500$, Finnish Cultural Foundation $€$ 4000, Finnish Pharmacists' Association, € 350, Finnish Pharmacists' Society € 200).

Open Access This article is licensed under a Creative Commons Attribution 4.0 International License, which permits use, sharing, adaptation, distribution and reproduction in any medium or format, as long as you give appropriate credit to the original author(s) and the source, provide a link to the Creative Commons licence, and indicate if changes were made. The images or other third party material in this article are included in the article's Creative Commons licence, unless indicated otherwise in a credit line to the material. If material is not included in the article's Creative Commons licence and your intended use is not permitted by statutory regulation or exceeds the permitted use, you will need to obtain permission directly from the copyright holder. To view a copy of this licence, visit http://creativecommons.org/licenses/by/4.0/.

\section{References}

1. Panesar SS, de Silva D, Carson-Stevens A, Cresswell KM, Salvilla SA, Slight SP, Javad S, Netuveli G, Larizgoitia I, Donaldson LJ, Bates DW, Sheikh A (2016) How safe is primary care? A systematic review. BMJ Qual Saf 25:544-553. https://doi.org/10.1136/ bmjqs-2015-004178

2. World Health Organization (2017) Medication without harm: WHO's third global patient safety challenge. World Health Organization http://www.who.int/patientsafety/medication-safety/ en/. Accessed 3/13 2018

3. Council of Europe, European Directorate for the Quality of Medicines and Health (2006) Creation of a better medication safety culture in Europe: building up safe medication practices. https:// www.edqm.eu/medias/fichiers/Report 2006.pdf. Accessed 9/11 2018

4. Pharmaceutical Care Network Europe (PCNE) (2017) Drug-related problem classification. https://www.pcne.org/working-groups/2/ drug-related-problem-classification. Accessed 09/11 2018 
5. Basger BJ, Moles RJ, Chen TF (2014) Application of drug-related problem (DRP) classification systems: a review of the literature. Eur J Clin Pharmacol 70:799-815. https://doi.org/10.1007/ s00228-014-1686-x

6. Dimitrow MS (2016) Development and validation of a drug-related problem risk assessment tool for use by practical nurses working with community-dwelling aged. Doctoral Dissertation, University of Helsinki. http://urn.fi/URN

7. Liberati A, Altman DG, Tetzlaff J, Mulrow C, Gotzsche PC, Ioannidis JPA, Clarke M, Devereaux PJ, Kleijnen J, Moher D (2009) The PRISMA statement for reporting systematic reviews and meta-analyses of studies that evaluate health care interventions: explanation and elaboration. J Clin Epidemiol 62:1-34. https://doi. org/10.1016/j.jclinepi.2009.06.006

8. Moher D, Shamseer L, Clarke M, Ghersi D, Liberati A, Petticrew M, Shekelle P, Stewart LA, PRISMA-P Group (2015) Preferred reporting items for systematic review and meta-analysis protocols (PRISMA-P) 2015 statement. Syst Rev 4:1-9. https://doi.org/10. 1186/2046-4053-4-1

9. Koecheler J (1989) Indicators for the selection of ambulatory patients who warrant pharmacist monitoring. Am J Hosp Pharm 46: 729-732

10. Dimitrow MS, Puustinen J, Viikari P, Puumalainen E, Vahlberg T, Airaksinen MSA, Kivelä S (2018) Can practical nurses identify older home care clients at risk of drug-related problemsGeriatricians' appraisal of their risk screenings: a pilot study. J Pharm Technol 34:99-108

11. Feinberg JL, Cameron KA, Lapane KL, Allsworth JE (2004) The use of GRAM ${ }^{\mathrm{TM}}$ software to improve patient safety in nursing facilities. Consult Pharm 19:398-413

12. Young WW, Bell JE, Bouchard VE, Duffy MG (1974) Clinical pharmacy services: prognostic criteria for selective patient monitoring. II. Am J Hosp Pharm 31:667-676. https://doi.org/10.1093/ ajhp/31.7.667

13. Young WW, Bell JE, Bouchard VE, Duffy MG (1974) Clinical pharmacy services: prognostic criteria for selective patient monitoring. I. Am J Hosp Pharm 31:562-568. https://doi.org/10.1093/ajhp/ 31.6.562

14. Sidel VW, Beizer JL, Lisi-Fazio D, Kleinmann K, Wenston J, Thomas C, Kelman HR (1990) Controlled study of the impact of educational home visits by pharmacists to high-risk older patients. $\mathrm{J}$ Community Health 15:163-174. https://doi.org/10.1007/ BF01350254

15. Barenholtz Levy H (2003) Self-administered medication-risk questionnaire in an elderly population. Ann Pharmacother 37:982-987. https://doi.org/10.1345/aph.1C305

16. Johnson KA, Nye M, Hill-Besinque K, Cody M (1995) Measuring of impact of patient counseling in the outpatient pharmacy setting: development and implementation of the counseling models for the Kaiser Permanente/USC Patient Consultation Study. Clin Ther 17: 988-1002. https://doi.org/10.1016/0149-2918(95)80077-8

17. Fuller D, Watson R (2005) Validating a self-medication risk assessment instrument. Clin Eff Nurs 9:78-83. https://doi.org/10.1016/j. cein.2004.12.003

18. Fuller D, Edmundson H (1996) Drug regimes: assessing patient compliance. Elder Care 8:22-24

19. Fuller D (1997) Preparation makes perfect. Nurs Times 93:44-45

20. Johnson M, Griffiths R, Piper M, Langdon R (2005) Risk factors for an untoward medication event among elders in communitybased nursing caseloads in Australia. Public Health Nurs 22:3644. https://doi.org/10.1111/j.0737-1209.2005.22106.x

21. Conn VS, Taylor SG, Kelley S (1991) Medication regimen complexity and adherence among older adults. Image J Nurs Sch 23: 231-235. https://doi.org/10.1111/j.1547-5069.1991.tb00677.x

22. Esposito L (1992) Medication knowledge and compliance. Home care vs. senior housing clients. Caring 11:42-45
23. Haynes RB, Taylor DW, Sackett DL, Gibson ES, Bernholz CD, Mukherjee J (1980) Can simple clinical measurements detect patient noncompliance? Hypertension 2:757-764. https://doi.org/10. 1161/01.HYP.2.6.757

24. Morisky DE, Green LW, Levine DM (1986) Concurrent and predictive validity of a self-reported measure of medication adherence. Med Care 24:67-74

25. Pfeiffer E (1975) A short portable mental status questionnaire for the assessment of organic brain deficit in elderly patients. J Am Geriatr Soc 23:433-441. https://doi.org/10.1111/j.1532-5415. 1975.tb00927.x

26. Romonko L, Pereles L (1992) An evaluation of pharmacy assessment for geriatric patients. Can J Hosp Pharm 45:15-20

27. George J, Munro K, McCaig D, Stewart D (2007) Risk factors for medication misadventure among residents in sheltered housing complexes. Br J Clin Pharmacol 63:171-176. https://doi.org/10. 1111/j.1365-2125.2006.02799.x

28. Townsend P (1979) Poverty in the United Kingdom: a survey of household resources and standards of living. Penguin, Harmondsworth

29. McGee MA, Johnson AL, Kay DW (1998) The description of activities of daily living in five centres in England and Wales. Medical Research Council Cognitive Function and Ageing Study. Age Ageing 27:605-613. https://doi.org/10.1093/ageing/27.5.605

30. Pit SW, Byles JE, Cockburn J (2007) Medication review: patient selection and general practitioner's report of drug-related problems and actions taken in elderly Australians. J Am Geriatr Soc 55:927934. https://doi.org/10.1111/j.1532-5415.2007.01181.x

31. Pit SW (2008) Prevalence of self-reported risk factors for medication misadventure among older people in general practice. J Eval Clin Pract 14:203-208. https://doi.org/10.1111/j.1365-2753.2007. 00833.x

32. Australian National Prescribing Service (2000) Medication Review. Prescribing Practice Review. No. 7. National Prescribing Service Ltd, Surry Hills

33. Gusdal AK, Beckman C, Wahlstrom R, Tornkvist L (2011) District nurses' use for an assessment tool in their daily work with elderly patients' medication management. Scand J Public Health 39:354360. https://doi.org/10.1177/1403494810396398

34. Lukazewski A, Mikula B, Servi A, Martin B (2012) Evaluation of a web-based tool in screening for medication-related problems in community-dwelling older adults. Consult Pharm 27:106-113. https://doi.org/10.4140/TCP.n.2012.106

35. Doucette WR, Chang EH, Pendergast JF, Wright KB, Chrischilles EA, Farris KB (2013) Development and initial assessment of the medication user self-evaluation (MUSE) tool. Clin Ther 35:344 350. https://doi.org/10.1016/j.clinthera.2013.02.010

36. Langford B, Jorgenson D, Kwan D, Papoushek C (2006) Implementation of a self-administered questionnaire to identify patients at risk for medication-related problems in a family health center. Pharmacotherapy 26:260-268. https://doi.org/10.1592/ phco.26.2.260

37. Akaike H (1973) Information theory and an extension of the maximum likelihood principle. In: Petrov B, Csaki F (eds) 2nd International Symposium on Information Theory. Akadémiai Kiadó, Budapest, Hungary, pp 267-281

38. Dimitrow MS, Mykkanen SI, Leikola SN, Kivela SL, Lyles A, Airaksinen MS (2014) Content validation of a tool for assessing risks for drug-related problems to be used by practical nurses caring for home-dwelling clients aged $>65$ years: a Delphi survey. Eur J Clin Pharmacol 70:991-1002. https://doi.org/10.1007/s00228-0141699-5

39. Dimitrow MS, Leikola SN, Kivela S, Passi S, Lukkari P, Airaksinen MSA (2015) Feasibility of a practical nurse administered risk assessment tool for drug-related problems in home care. Scand J 
Public Health 43:761-769. https://doi.org/10.1177/ 1403494815591719

40. Dimitrow MS, Airaksinen MS, Kivela SL, Lyles A, Leikola SN (2011) Comparison of prescribing criteria to evaluate the appropriateness of drug treatment in individuals aged 65 and older: a systematic review. J Am Geriatr Soc 59:1521-1530. https://doi.org/10. 1111/j.1532-5415.2011.03497.x

41. Barenholtz Levy H, Steffen AM (2016) Validating the medication risk questionnaire with family caregivers of older adults. Consult Pharm 31:329-337. https://doi.org/10.4140/TCP.n.2016.329

42. Malone DC, Carter BL, Billups SJ, Valuck RJ, Barnette DJ, Sintek CD, Okano GJ, Ellis S, Covey D, Mason B, Jue S, Carmichael J, Guthrie K, Sloboda L, Dombrowski R, Geraets DR, Amato MG (2001) Can clinical pharmacists affect SF-36 scores in veterans at high risk for medication-related problems? Med Care 39:113-122

43. Carter BL, Malone DC, Valuck RJ, Barnette DJ, Sintek CD, Billups SJ (1998) The IMPROVE study: background and study design. Impact of Managed Pharmaceutical Care on Resource Utilization and Outcomes in Veterans Affairs Medical Centers. Am J HealthSyst Pharm 55:62-67

44. Carter BL, Malone DC, Billups SJ, Valuck RJ, Barnette DJ, Sintek CD, Ellis S, Covey D, Mason B, Jue S, Carmichael J, Guthrie K, Dombrowski R, Geraets DR, Amato M (2001) Interpreting the findings of the IMPROVE study. Am J Health-Syst Pharm 58: $1330-1337$

45. Ellis SL, Carter BL, Malone DC, Billups SJ, Okano GJ, Valuck RJ, Barnette DJ, Sintek CD, Covey D, Mason B, Jue S, Carmichael J, Guthrie K, Dombrowski R, Geraets DR, Amato M (2000) Clinical and economic impact of ambulatory care clinical pharmacists in management of dyslipidemia in older adults: the IMPROVE study. Impact of managed pharmaceutical care on resource utilization and outcomes in Veterans Affairs Medical Centers. Pharmacotherapy 20:1508-1516

46. Ellis SL, Billups SJ, Malone DC, Carter BL, Covey D, Mason B, Jue S, Carmichael J, Guthrie K, Sintek CD, Dombrowski R, Geraets DR, Amato M (2000) Types of interventions made by clinical pharmacists in the IMPROVE study. Impact of managed pharmaceutical care on resource utilization and outcomes in Veterans Affairs Medical Centers. Pharmacotherapy 20:429-435

47. Malone DC, Carter BL, Billups SJ, Valuck RJ, Barnette DJ, Sintek CD, Okano GJ, Ellis S, Covey D, Mason B, Jue S, Carmichael J, Guthrie K, Sloboda L, Dombrowski R, Geraets DR, Amato MG (2000) An economic analysis of a randomized, controlled, multicenter study of clinical pharmacist interventions for high-risk veterans: the IMPROVE study. Impact of managed pharmaceutical care resource utilization and outcomes in Veterans Affairs Medical Centers. Pharmacotherapy 20:1149-1158

48. Moore A, Patterson C, White J, House ST, Riva JJ, Nair K, Brown A, Kadhim-Saleh A, McCann D (2012) Interprofessional and integrated care of the elderly in a family health team. Can Fam Physician 58:e436-e441

49. Tan E, Stewart K, Elliott RA, George J (2012) An exploration of the role of pharmacists within general practice clinics: the protocol for the pharmacists in practice study (PIPS). BMC Health Serv Res 12: 246. https://doi.org/10.1186/1472-6963-12-246

50. Toivo T, Dimitrow M, Puustinen J, Savela E, Pelkonen K, Kiuru V, Suominen T, Kinnunen S, Uunimaki M, Kivela S, Leikola S, Airaksinen M (2018) Coordinating resources for prospective medication risk management of older home care clients in primary care: procedure development and RCT study design for demonstrating its effectiveness. BMC Geriatr 18:74. https://doi.org/10.1186/s12877018-0737-z

51. Almanasreh E, Moles R, Chen TF (2018) Evaluation of methods used for estimating content validity. Res Social Adm Pharm 2:214221. https://doi.org/10.1016/j.sapharm.2018.03.066

52. Marriott J, Stehlik P (2012) A critical analysis of the methods used to develop explicit clinical criteria for use in older people. Age Ageing 41:441-450. https://doi.org/10.1093/ageing/afs064

53. Devik SA, Olsen RM, Fiskvik IL, Halbostad T, Lassen T, Kuzina N, Enmarker I (2018) Variations in drug-related problems detected by multidisciplinary teams in Norwegian nursing homes and home nursing care. Scand J Prim Health Care 3:291-299. https://doi.org/ 10.1080/02813432.2018.1499581

54. Leikola SNS, Virolainen J, Tuomainen L, Tuominen RK, Airaksinen MSA (2012) Comprehensive medication reviews for elderly patients: findings and recommendations to physicians. J Am Pharm Assoc (2003) 52:630-633. https://doi.org/10.1331/ JAPhA.2012.10163

55. National Institute for Health and Care Excellence (NICE) (2015) NICE Guideline (NG5) Medicines optimisation: the safe and effective use of medicines to enable the best possible outcomes. NICE. https://www.nice.org.uk/guidance/ng5. Accessed 08/10 2018

56. Rankin A, Cadogan CA, Ryan C, Clyne B, Smith SM, Hughes CM (2018) Core outcome set for trials aimed at improving the appropriateness of polypharmacy in older people in primary care. J Am Geriatr Soc 66:1206-1212. https://doi.org/10.1111/jgs.15245

Publisher's note Springer Nature remains neutral with regard to jurisdictional claims in published maps and institutional affiliations. 